УДК 621.391

ШТОМПЕЛЬ М. А., д.Т.н., доцент, ПАРПУРА С. Ю., студент (УкрДУЗТ)

\title{
Аналіз особливостей застосування оптичних волокон у телекомунікаційній інфраструктурі залізничного транспорту
}

Наведено конструкиію та профілі показників заломлення одномодових та багатомодових оптичних волокон. Проаналізовано вплив параметрів передачі оптичних волокон на якість надання послуг у телекомунікаційній інфраструктурі залізничного транспорту. Розглянуто вікна прозорості та спектральні діапазони для оптичних волокон, щзо використовуються у різноманітних телекомунікаційних технологіях. Надано класифікацію оптичних волокон та галузі їх застосування при побудові сучасних телекомунікаційних систем та мереж залізничного транспорту.

Ключові слова: оптичні волокна, телекомунікаційна інфраструктура, залізничний транспорт, параметри передачi.

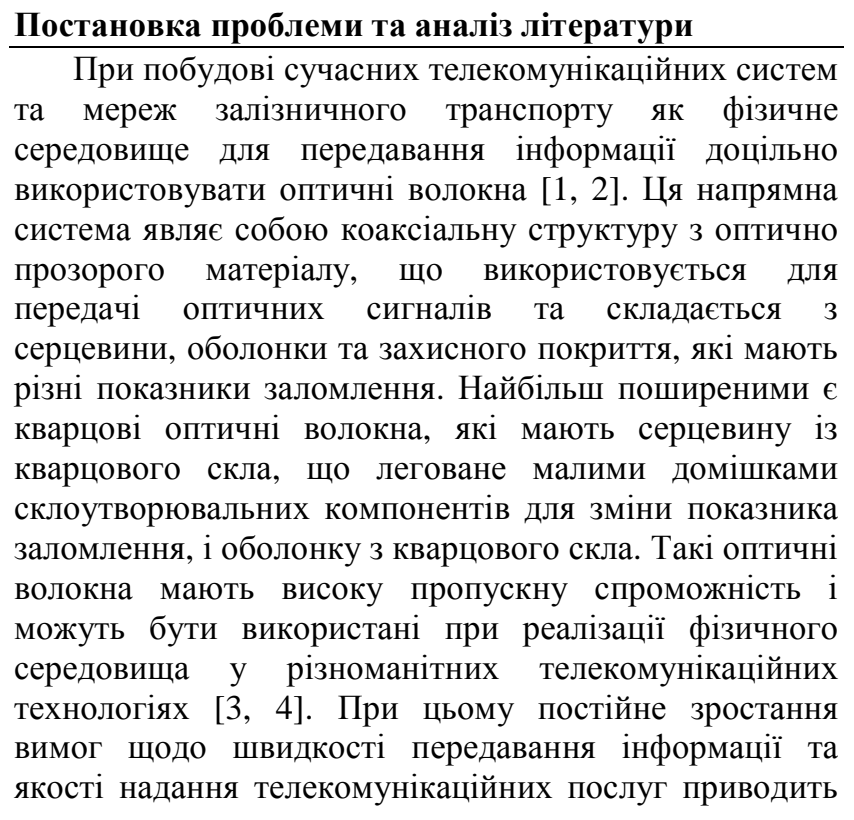

до необхідності застосування оптичних волокон різних типів.

Тому актуальним завданням є розгляд питань, що стосуються аналізу особливостей конструкції та параметрів передавання оптичних волокон різних типів.

Мета статті - визначення особливостей конструкції та параметрів передавання оптичних волокон різних типів, що застосовуються при створенні сучасної телекомунікаційної інфраструктури залізничного транспорту.

\section{Основна частина \\ Для створення фізичного середовища} телекомунікаційної інфраструктури залізничного транспорту застосовуються два основних типи кварцових оптичних волокон - багатомодове та одномодове, типова конструкція яких наведена на рис. 1.

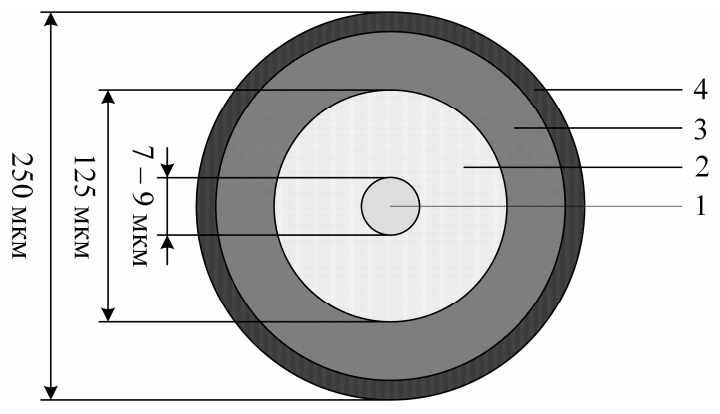

б)

Рис. 1. Конструкція оптичного волокна: а - багатомодове; б - одномодове;

1 - серцевина; 2 - оболонка; 3 - внутрішній шар захисного покриття; 4 - зовнішній шар захисного покриття

(C) М. А. Штомпель, С. Ю. Парпура, 2019 
Профіль показника заломлення характеризує зміни показника вздовж радіуса оптичного волокна і має різну форму залежно від типу волокна (рис. 2).

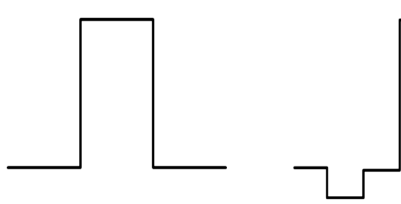

a)

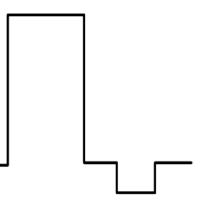

б)

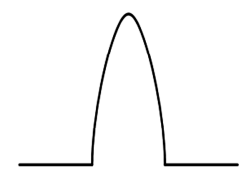

B)

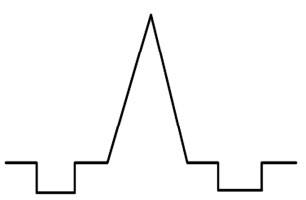

г)

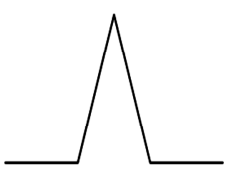

д)

Рис. 2. Профілі показника заломлення оптичних волокон: а, б - східчастий; в - градієнтний; г - сегментний; д - трикутний

До основних параметрів передачі оптичних волокон належать: згасання; дисперсія (смуга пропускання); нелінійні спотворення [1 - 4].

Величина згасання в оптичному волокні описує зменшення інтенсивності випромінювання в міру його проходження по волокну. Оптичні втрати, що обумовлюють згасання оптичного сигналу в кварцовому оптичному волокні, визначаються, в основному, трьома факторами: поглинанням випромінювання матеріалом, релеєвським розсіюванням, втратами на випромінювання.

Другою найважливішою характеристикою оптичного волокна, з точки зору застосування його у телекомунікаційній інфраструктурі, є дисперсія розсіювання в часі i в просторі спектральних або модових складових оптичного імпульсу, що веде до збільшення його тривалості при розповсюдженні по довжині оптичного волокна. Явище дисперсії призводить до того, що при проходженні послідовності прямокутних імпульсів (цифрового сигналу) через певну довжину оптичного волокна імпульси будуть розширюватися i, в підсумку, стане неможливим розділення двох сусідніх імпульсів, тобто виникнуть помилки передачі. Таким чином, дисперсія $\epsilon$ основним фактором, що обмежує пропускну спроможність або ширину смуги пропускання оптичного волокна.

Три механізми дисперсії $\epsilon$ причинами, що зменшують ширину смуги пропускання оптичного волокна: міжмодова дисперсія; хроматична дисперсія; поляризаційна модова дисперсія.

Відносний вплив кожного 3 цих механізмів залежить від виду оптичного волокна, типу джерела випромінювання та швидкості передачі.

Міжмодова дисперсія обумовлена різною швидкістю поширення мод у волокні і виникає в багатомодових оптичних волокнах. Величина міжмодової дисперсії визначається, в основному, профілем показника заломлення оптичного волокна.

Хроматична дисперсія виникає через відмінності швидкостей розповсюдження довжин хвиль, складових спектра джерела випромінювання, що призводить до розширення імпульсу. У величину хроматичної дисперсії внесок роблять дві складові: матеріальна та хвилевідна дисперсії. Матеріальна дисперсія може розглядатися як розширення імпульсу при його поширенні через масив скла, що обумовлено залежністю показника заломлення скла серцевини оптичного волокна від довжини хвилі. Хвилевідна дисперсія пов'язана 3 напрямними властивостями волокна і визначається залежністю групової швидкості мод від довжини хвилі випромінювання. Ступінь цієї залежності визначається хвилевідною структурою волокна: геометричними розмірами серцевини i формою профілю показника заломлення, а також шириною спектра випромінювання джерела.

Поляризаційна модова дисперсія характеризується часом диференціальної групової затримки між двома ортогонально-поляризованими модами, що приводить до розширення імпульсу. Причиною виникнення такої дисперсії $є$ невелика асиметрія поперечного перерізу, яка завжди буває в реальних оптичних волокнах, i напруги, яким ці волокна піддаються. Величина цієї дисперсії визначається комбінацією двох факторів: лінійного двопроменезаломлення та взаємодією мод.

Нелінійні оптичні ефекти виникають у результаті взаємодії електромагнітного випромінювання світлової хвилі 3 передавальним середовищем матеріалом оптичного волокна Ці ефекти починають проявлятися в умовах високої інтенсивності світлового сигналу та великої протяжності ліній, оскільки нелінійна взаємодія накопичується вздовж всієї довжини ділянки лінії зв'язку. Взаємодія світлового сигналу і кварцового середовища оптичного волокна призводить до виникнення цілого ряду нелінійних ефектів, які можуть бути поділені на дві категорії:

- розсіювальні ефекти (вимушене бріллюенівське розсіювання, вимушене раманівське розсіювання);

- ефекти, що мають природу ефекту Керра, тобто зміна показника заломлення середовища залежно від інтенсивності випромінювання, що передається (фазова самомодуляція, фазова крос-модуляція, чотирихвильове змішування) [5].

Вікна прозорості та спектральні діапазони оптичних волокон, що використовуються при побудові сучасних телекомунікаційних систем та мереж залізничного транспорту на основі оптичних волокон, наведені у табл. 1. 
Вікна прозорості та спектральні діапазони оптичних волокон

\begin{tabular}{|c|c|c|c|}
\hline $\begin{array}{c}\text { Вікно } \\
\text { прозорості }\end{array}$ & $\begin{array}{c}\text { Умовне позначення спектрального } \\
\text { діапазону }\end{array}$ & $\begin{array}{c}\text { Найменування } \\
\text { діапазону }\end{array}$ & $\begin{array}{c}\text { Діапазон довжин хвиль, } \\
\text { нм }\end{array}$ \\
\hline 1 & - & - & $780-860$ \\
\hline 2 & $\mathrm{O}$ & Основний & $1260-1360$ \\
\hline- & $\mathrm{E}$ & Розширений & $1360-1460$ \\
\hline 5 & $\mathrm{~S}$ & Короткохвильовий & $1460-1530$ \\
\hline 3 & $\mathrm{C}$ & Стандартний & $1530-1565$ \\
\hline 4 & $\mathrm{~L}$ & Довгохвильовий & $1565-1625$ \\
\hline- & $\mathrm{U}$ & Наддовгохвильовий & $1625-1675$ \\
\hline
\end{tabular}

Для побудови телекомунікаційної інфраструктури залізничного транспорту використовуються багатомодові та одномодові оптичні волокна, класифікація та особливості яких наведено нижче.

Як відомо, у багатомодових оптичних волокнах одночасно поширюється велика кількість мод. При цьому можна виділити два види багатомодових волокон: із ступінчастим і градієнтним профілем показника заломлення серцевини. Ці види оптичних волокон розрізняються параметрами передачі, особливо значенням міжмодової дисперсії. Параметри багатомодових градієнтних оптичних волокон регламентуються рекомендацією MCE-T G.651 і часто називаються волокнами класу G.651.

Багатомодові волокна оптимізовані для роботи на довжинах хвиль 850 i 1310 нм. Ці волокна характеризуються великим діаметром серцевини (50 мкм) та високою числовою апертурою $(0,2-0,37)$, що дозволяє вводити в волокно велику потужність і полегшує операцію зрощування волокон. Велика ширина смуги пропускання градієнтних волокон $(400-1000$ МГц-км) забезпечується жорстким технологічним контролем форми (параболічної) профілю показника заломлення i волокна. Такі волокна, в основному, застосовуються в локальних телекомунікаційних мережах, об'єктових лініях зв'язку та при побудові систем автоматизації залізничного транспорту.

Потреба у збільшенні смуги пропускання $\mathrm{i}$ дальності передачі сигналу сприяла необхідності створення одномодового оптичного волокна, діаметр серцевини і співвідношення показників заломлення серцевини і оболонки якого обрані таким чином, що в ньому може поширюватися тільки одна мода.

Розвиток телекомунікацій у напрямку збільшення швидкості та дальності передачі спричинив створення декількох типів одномодових волокон, які можна класифікувати, зокрема, за таким критерієм, як хроматична дисперсія, що залежить від профілю показника заломлення [6, 7].

Згідно 3 рекомендаціями МСЕ-Т виокремлюють такі класи (види) одномодових волокон:

1) G.652 - оптичні волокна 3 незміщеною дисперсією 3 довжиною хвилі нульової дисперсії та довжиною хвилі відсічення в області 1310 нм;

2) G.653 - оптичні волокна зі зміщеною дисперсією 3 довжиною хвилі нульової дисперсії в області 1550 нм та довжиною хвилі відсічення в області 1310 нм, що оптимізовані для роботи у спектральному діапазоні C;

3) G.654 - оптичні волокна 3 мінімізованими втратами 3 довжиною хвилі нульової дисперсії в області 1310 нм та 3 довжиною хвилі відсічення в області 1550 нм, що оптимізовані для роботи у спектральному діапазоні C;

4) G.655 - оптичні волокна 3 ненульовою зміщеною дисперсією, що оптимізовані для роботи у спектральному діапазоні C;

5) G.656 - оптичні волокна 3 ненульовою дисперсією, що оптимізовані для роботи у спектральних діапазонах S, C, L;

6) G.657 - оптичні волокна, що не чутливі до вигинів та оптимізовані для роботи у спектральному діапазоні $\mathrm{C}$.

У свою чергу в кожному класі оптичних волокон виділяють підкласи, що характеризуються деякими відмінностями у параметрах передачі та галузі використання.

При створенні телекомунікаційної інфраструктури залізничного транспорту найбільшого поширення набули одномодові оптичні волокна класу G.652, також на деяких ділянках транспортної мережі застосовуються оптичні волокна класів G.655 та G.656. Слід зазначити, що перспективним напрямом розвитку телекомунікаційних мереж доступу залізничного транспорту є перехід до технології пасивних оптичних мереж PON та застосування оптичних волокон класу G.657.

Також при створенні нових оптичних сегментів телекомунікаційної інфраструктури залізничного транспорту при переході до новітніх технологій доцільно застосовувати спеціальні типи волокон:

- оптичні волокна для компенсації дисперсії, що застосовуються в модулях компенсації дисперсії;

- оптичні волокна 3 домішкою рідкоземельних елементів, що застосовуються в оптичних підсилювачах; 
- оптичні волокна, що зберігають стан поляризації випромінювання, які застосовуються в поляризаційних дільниках і змішувачах [5 - 7].

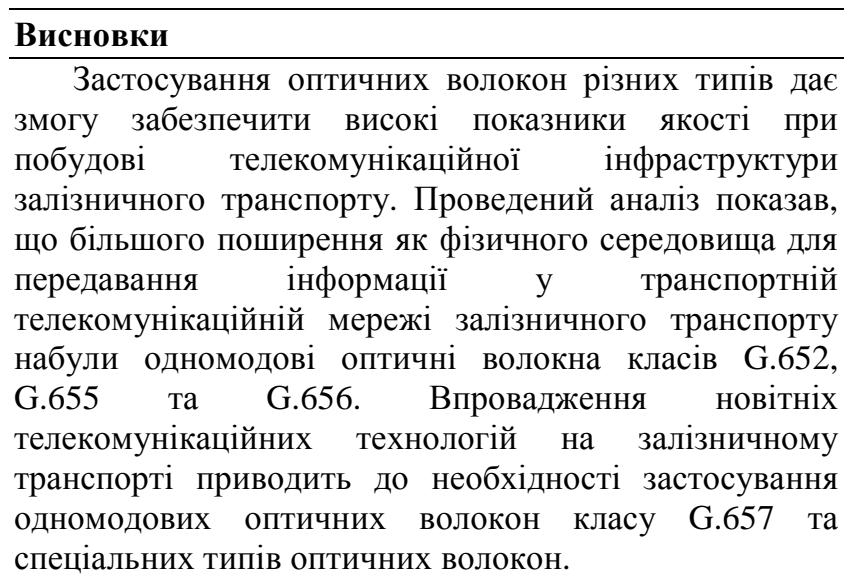

Список використаних джерел

1. Листвин А. В., Листвин В.Н., Швырков Д. В. Оптические волокна для линий связи. Москва: ЛЕСАР Арт, 2003. 288 с.

2. Волков О. С., Жученко О. С., Полянськова Н. В., Чітак К. В., Цапенко К. Е. Дослідження принципів побудови цифрових систем комутації мереж оперативно-технологічного зв'язку. 3б. наук. праць Укр. держ. акад. залізнич. трансп. 2013. Вип. 142. C. $235-241$.

3. Фриман Р. Волоконно-оптические системы связи : пер. с англ.; под ред. Н. Н. Слепова. Москва : Техносфера, 2003. 590 с.

4. Фокин, В. Г. Оптические системы передачи и транспортные сети : учеб. пособ. Москва : ЭкоТрендз, 2008. 267 с.

5. Sabella R. Performance analysis of wireless broadband systems employing optical fiber links. IEEE Transactions on Communications. 1999. Vol. 47, Issue 5. P. 715 - 721.

6. Batagelj B., Janyani V., Tomažič S. Research challenges in optical communications towards 2020 and beyond. Journal of Microelectronics, Electronic Components and Materials. 2014. Vol. 44, No. 3. P. $177-184$.

7. Biberman A., Bergman K. Optical interconnection networks for high-performance computing systems. Reports on Progress in Physics. 2012. Vol. 75, Number 4. P. $1-15$.

\footnotetext{
Штомпель Н. А., Парпура С. Ю. Анализ особенностей применения оптических волокон В телекоммуникационной железнодорожного транспорта.

Приведены конструкции и профили показателей преломления одномодовых и многомодовых
}

оптических волокон. Проанализировано влияние параметров передачи оптических волокон на качество предоставления услуг в телекоммуникационной инфраструктуре железнодорожного транспорта. Рассмотрены окна прозрачности и спектральные диапазоны для оптических волокон, используемые в различных телекоммуникационных технологиях. Представлена классификация оптических волокон и области их применения при построении современных телекоммуникационных систем и сетей железнодорожного транспорта.

Ключевые слова: оптические волокна, телекоммуникационная инфраструктура, железнодорожный транспорт, параметры передачи.

Shtompel M., Parpura S. Analysis of application features of optical fibers in railway transport telecommunications infrastructure.

It is shown that it is advisable to use optical fibers as a physical medium for the information transmission in the construction of modern telecommunication systems and networks of railway transport. It is determined that multimode and single-mode optical fibers are used to create the physical medium of the telecommunication infrastructure of railway transport. The design and profiles of refractive indices of optical fibers are given. It is shown that the main parameters of optical fiber transmission are attenuation, dispersion (bandwidth) and nonlinear distortions. The main causes of optical signal attenuation are absorption of radiation by optical fiber material, Rayleigh scattering and radiation loss. It is determined that the dispersion of optical signals consists of inter-mode dispersion, chromatic dispersion and polarization mode dispersion. It is shown that nonlinear effects in optical fiber can be divided into scattering effects and effects related to changes in the refractive index depending on the radiation intensity. The influence of optical fiber transmission parameters on the quality of service provision in the railway telecommunication infrastructure has been analyzed. Transparency windows and spectral ranges for optical fibers used in various telecommunication technologies are considered. The classification of singlemode and multi-mode optical fibers according to ITU-T recommendations is presented. The features of each class of optical fibers are analyzed. The fields of application of optical fibers of different classes in the construction of modern telecommunication systems and networks of railway transport are presented.

Keywords: optical fibers, telecommunication infrastructure, railway transport, transmission parameters.

Надійила 09.09.2019 p. 
Штомпель Микола Анатолійович, доктор технічних наук, дочент, дочент кафедри транспортного зв'язку, Украӥнський державний університет залізничного транспорту, Харків, Украӥна. E-mail-tz@kart.edu.иа ORCID ID: https://orcid.org/0000-0003-3132-8335

Парпура Світлана Юріївна, студентка, Украӥнський державний університет залізничного транспорту, Харків, Україна. E-mail - tz@kart.edu.ua. ORCID ID: https://orcid.org/0000-0002-9858-4846

Shtompel Mykola Anatoliiovych, Doctor of sciences (engineering), Associate professor (docent), Associate professor, Department of transport communication, Ukrainian State University of Railway Transport, Kharkiv, Ukraine. E-mail - tz@kart.edu.ua. ORCID ID: https://orcid.org/0000-0003-3132-8335

Parpura Svitlana Yuriivna, student, Ukrainian state university of railway transport, Kharkiv, Ukraine. E-mail tz@kart.edu.ua. ORCID ID: https://orcid.org/0000-0002$\underline{9858-4846}$ 